\title{
Assessing uncertainty in radar measurements on simplified meteorological scenarios
}

\author{
L. Molini, A. Parodi, N. Rebora, and F. Siccardi \\ CIMA, University of Genoa, Savona, Italy
}

Received: 11 November 2005 - Revised: 25 December 2005 - Accepted: 16 January 2006 - Published: 20 February 2006

\begin{abstract}
A three-dimensional radar simulator model (RSM) developed by Haase (1998) is coupled with the nonhydrostatic mesoscale weather forecast model Lokal-Modell (LM). The radar simulator is able to model reflectivity measurements by using the following meteorological fields, generated by Lokal Modell, as inputs: temperature, pressure, water vapour content, cloud water content, cloud ice content, rain sedimentation flux and snow sedimentation flux. This work focuses on the assessment of some uncertainty sources associated with radar measurements:
\end{abstract}

1. absorption by the atmospheric gases, e.g., molecular oxygen, water vapour, and nitrogen;

2. attenuation due to the presence of a highly reflecting structure between the radar and a "target structure".

RSM results for a simplified meteorological scenario, consisting of a humid updraft on a flat surface and four cells placed around it, are presented.

\section{Introduction}

The use of weather radars is relevant for both precipitation rate retrieval and data assimilation purposes because of their capability to provide measures of dynamical and microphysical states at high temporal and spatial resolution. Nevertheless, a wide range of uncertainty sources affect radar measurements and their products, challenging their reliability. Since early 90 s, numerical simulations of radar measurements have provided a suitable tool to investigate some of the main aspects of this issue. For instance, a complex work on influence of drop size distribution and X-band attenuation on reflectivity was carried out by Chandrasekar and Bringi (1990), the importance of measurement volume variations depending on increasing radar distance has been assessed by Fabry et al. (1992), uncertainty due to empirical

Correspondence to: L. Molini

(luca.m@cima.unige.it)
Z-R relations has been analysed by Krajewski and Anagnostou (1997) and bright band effects on reflectivity were studied by Skaropoulos and Russchenberg (2002). Krajewski and Chandrasekar (1993) simulated radar reflectivity for realistic rainfall events using a stochastic space-time model for precipitation and a statistically generated drop size distribution (DSD), while Haase and Crewell (2001) used the three dimensional fields of atmospheric variables generated by a numerical weather prediction model (see also Keil and Hagen, 2000; Meetschen and Crewell, 2000).

In order to assess some basic uncertainty sources (like gaseous absorption and screening effect of a precipitating structure located between the radar and a "target" structure), the latter approach is followed. A simplified atmospheric scenario is generated by the Lokal-Modell (LM) and standard radar products like plan position indicator (PPI) and range height indicator (RHI) scans have been simulated by RSM. Simulations have been performed either considering uncertainty sources or not taking these factors into account so as to compare data and gain an assessment of their influence on radar measurements. This work is organized as follows: Sects. 2 and 3 give a brief overview of Lokal-Modell and Radar Simulation Model, Sect. 4 shows simulation results and quantitative analysis on them and finally, Sect. 5 contains conclusion and future outlooks.

\section{The Lokal-Modell}

The numerical simulations shown in this work have been performed with Lokal-Modell which is a non-hydrostatic numerical weather prediction model developed by Deutsche Wetterdienst (DWD, the German National Weather Service) since 1998 (Doms and Schättler, 1998); it is fully compressible, using hybrid terrain-following coordinates, having a maximum horizontal spatial resolution of $50 \mathrm{~km}$, while the vertical resolution may vary from a value of $50 \mathrm{~m}$ near surface up to several hundred metres with increasing altitude. The basic prognostic model variables are wind vector, 
temperature, pressure perturbation, specific humidity and cloud liquid water, while rain and snow fluxes are diagnostic variables. Lokal-Modell can use a wide range of microphysical schemes spacing from the Kessler (warm rain) scheme to the 3-category ice scheme. For a more comprehensive description of the model, the reader is referred to Steppeler et al. (2003).

In this work we operate:

- a $1 \mathrm{~km}$ horizontal spacing grid

- a regularly spaced vertical grid $(\Delta z=200 \mathrm{~m})$

- a 2 category ice scheme which can model 5 microphysical species: rain, snow, cloud water, cloud ice, water vapour and the microphysical processes related to.

\section{The Radar Simulator Model}

The Radar Simulator Model (RSM) is able to simulate the most important atmospheric interactions of an electromagnetic wave with hydrometeors, e.g. backscattering and attenuation. In order to calculate the volume backscattering and extinction cross sections, some of the three-dimensional fields of Lokal-Modell outputs are required:

1. rain sedimentation flux $\left[\mathrm{kg} / \mathrm{m}^{-2} \mathrm{~s}\right]$

2. snow sedimentation flux $\left[\mathrm{kg} / \mathrm{m}^{-2} \mathrm{~s}\right]$

3. temperature $[\mathrm{K}]$

4. pressure $[\mathrm{Pa}]$

5. cloud ice specific content $[\mathrm{kg} / \mathrm{kg}]$

6. cloud water specific content $[\mathrm{kg} / \mathrm{kg}]$

7. water vapour ratio $[\mathrm{kg} / \mathrm{kg}]$

The second step consists of applying the Mie scattering theory (Mie, 1908) by which

$\kappa=\frac{\lambda^{3}}{8 \pi^{2}} \int_{0}^{\infty} \chi^{2} N(\chi) \xi(\chi) d \chi$

where:

- $\kappa$ represents the volume absorption, scattering or extinction coefficient depending on which efficiency factor $\xi$ (absorption, scattering or extinction) is inserted in the integrand

$-\chi=2 \pi / \lambda$ is the dimensionless shape factor

- $N(\chi)$ represents the drop size distribution (DSD)

While rain and snow are assumed to have exponential DSDs in the LM (Marshall-Palmer, 1949 and Gunn-Marshall, respectively), a cloud DSD is not resolved: therefore RSM defines a DSD for cloud liquid water taking a cumulus or a cirrostratus DSD from literature (Chylek and Ramaswamy, 1982 for cloud water and Ulaby et al., 1981 for cloud ice). The calculation of extinction cross section is performed by using the millimeter-wave propagation model from Liebe et al. (1989) which allows to consider the effects of absorption by atmospheric gases (e.g., molecular oxygen, water vapour and nitrogen). When all the contributions to the total extinction cross section have been calculated, the backscattered power from the scanned volume to the radar can be expressed as follows

$P_{r}=C_{\text {rad }} \frac{1}{R^{4}} V_{p} \kappa_{\text {back }} \exp \left(-2 \int_{0}^{R} \kappa_{\text {ext }} d R\right)$

where:

$-C_{\text {rad }}\left[\mathrm{m}^{2}\right]$ is the radar constant

$-R[\mathrm{~m}]$ is the range to the scattering volume

- $V_{p}\left[\mathrm{~m}^{3}\right]$ is the pulse volume at range $R$.

A relation between received power and reflectivity factor was determined by assuming only liquid particles (an equivalent radius is calculated for snow) and pure Rayleigh scattering:

$P_{r}=C_{r a d} \frac{1}{R^{4}} V_{p} 10^{-10} \frac{\pi^{5}}{\lambda^{4}}|K|^{2} Z$

where:

- $|K|^{2}=0.93$ is the dimensionless refraction constant for water

$-\lambda$ is the wavelength $[\mathrm{cm}]$.

Considering both Eqs. (2) and (3) leads to the form below:

$Z_{\text {sim }}=10 \frac{\lambda^{4}}{\pi^{5}} \kappa_{\text {back }} \exp \left(-2 \int_{0}^{R} \kappa_{\text {ext }} d R\right)$

Commonly, radar reflectivity is measured in $\mathrm{dBZ}=10 \log _{10}$ (Z).

RSM output consists of simulated PPI or RHI scans which actually consider radar beam geometry (and its effects on measurements) Moreover, RSM can calculate a reflectivity value for each domain grid point (reflectivity volume), just by summing up the contribution of each microphysical species without considering any physical interference to the measure. In practice, the true reflectivity value for each grid point is provided.

\section{Numerical experiments}

The characterization of uncertainty in radar measurements is addressed by using, as atmospheric target scenario, a system of deep convective structures over an aquaplanet. The numerical simulations are initialized considering a horizontally homogeneous atmosphere in which we locate: 


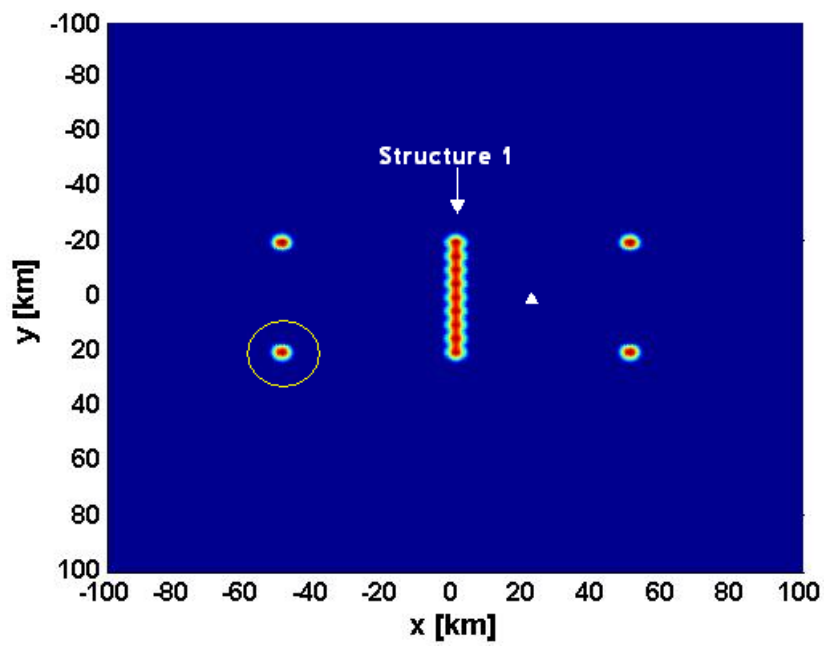

Fig. 1. Horizontal section of initial temperature 3-D field at $100 \mathrm{~m}$ quota. The dotted circle marks the "target cell", while the white triangle shows the radar position.

- STRUCTURE 1: an ascending current of humid air, whose volume is $10 \times 40 \times 1 \mathrm{~km}$, centred on domain mean section, warmer $\left(\Delta \mathrm{T}_{\max }=1 \mathrm{~K}\right)$ than the environment.

- STRUCTURES 2-3-4-5: four axially symmetric thermal perturbations (warm bubbles) of vertical radius $1000 \mathrm{~m}$ and horizontal radius $10 \mathrm{~km}$. The amplitude of the temperature perturbation is maximum in the cell's centre $(1 \mathrm{~K})$ and gradually decreases on approaching the bubble boundaries.

Both kind of structures were used so as to trigger deep moist convection generating high intensity precipitating structures. Figure 1 shows that the computational domain size is $200 \times 200 \times 20 \mathrm{~km}$, having the same horizontal $(1 \mathrm{~km})$ and vertical $(200 \mathrm{~m})$ resolution features mentioned in Sect. 2. Finer resolution experiments will be carried out later on. The vertical profile of temperature and humidity inside the computational domain are defined according to Weisman and Klemp (1982, 1984), corresponding to convective available potential energy of about $3000 \mathrm{~J} / \mathrm{kg}$, while neither wind shear nor orography effects are taken into account.

\subsection{First experiment-gaseous (nitrogen, molecular oxygen, water vapour) absorption effect}

To point out only the effects of gaseous absorption, the presence of the ascending current between radar and the selected target cell is not considered. In this first test, we compare:

1. horizontal and vertical sections of the reflectivity volume (see Sect. 3) after regridding them on the same polar grid of PPI and RHI scans, respectively.

2. both PPI and RHI scans of RSM obtained by taking into account the geometry of the radar beam

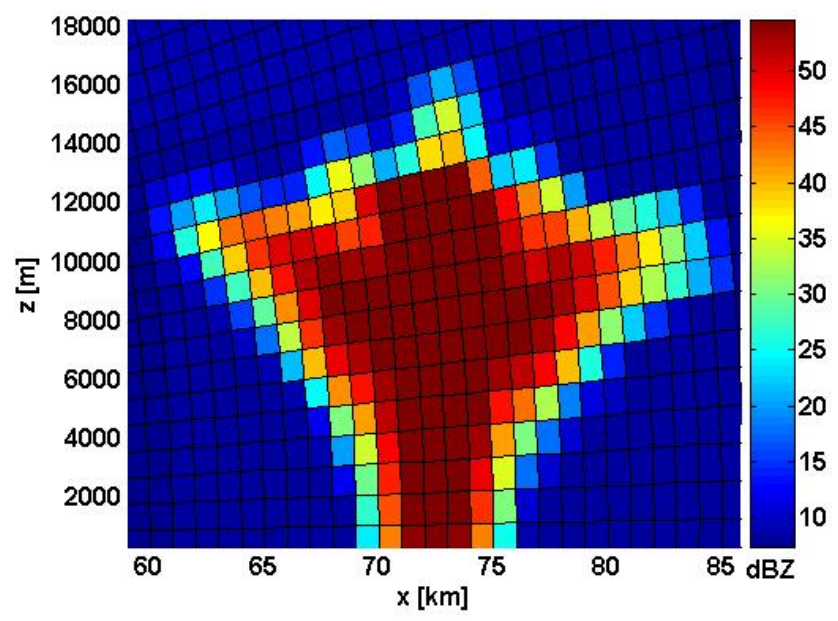

Fig. 2. Vertical section of the volume reflectivity regridded on the RHI scan polar grid: the "target cell".

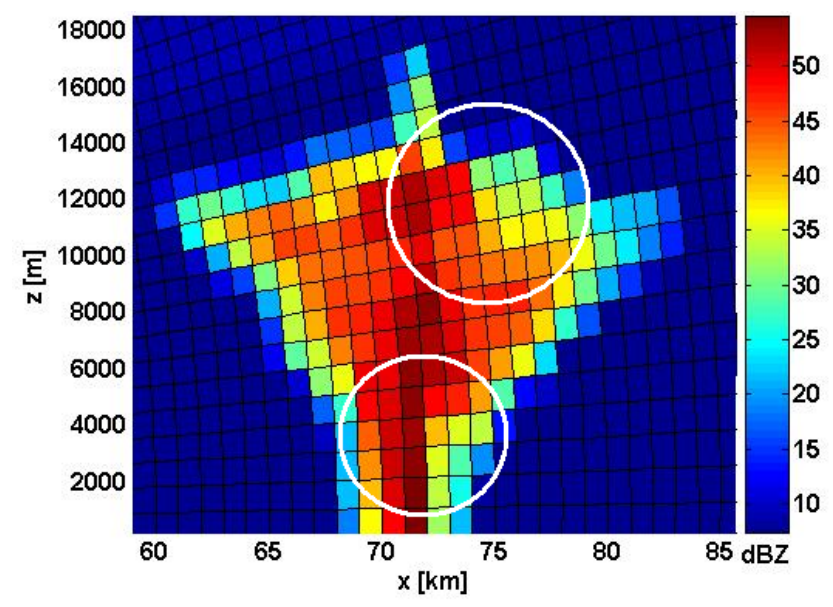

Fig. 3. RHI scan of the target cell. Maximum elevation angle: $30^{\circ}$.

In other words, Fig. 2 shows what we should see if we could be able to perform "perfect" radar scans measuring reflectivity for each domain grid point without any atmospheric interference. Dotted white circles in Fig. 3 show the regions where radar signal loss is more evident. Then, Fig. 4 displays the vertical reflectivity profile of both regridded volume and RHI scan. The mean difference is about $5 \mathrm{dBZ}$ (45 vs $40 \mathrm{dBZ}$ ) which means $24 \mathrm{vs} 12 \mathrm{~mm} / \mathrm{h}$ in terms of precipitation rate, using Marshall-Palmer (1948) relation. Very similar results have been found by performing comparisons between PPI scans and horizontal regridded sections of the reflectivity volume.

\subsection{Second experiment - screening effect}

The second experiment is devoted to measuring the screening effects of an intense precipitating structure located (i.e. Structure 1) between the radar and the target cell: in order to retrieve differences, PPI and RHI scans are performed, in which alternately: 


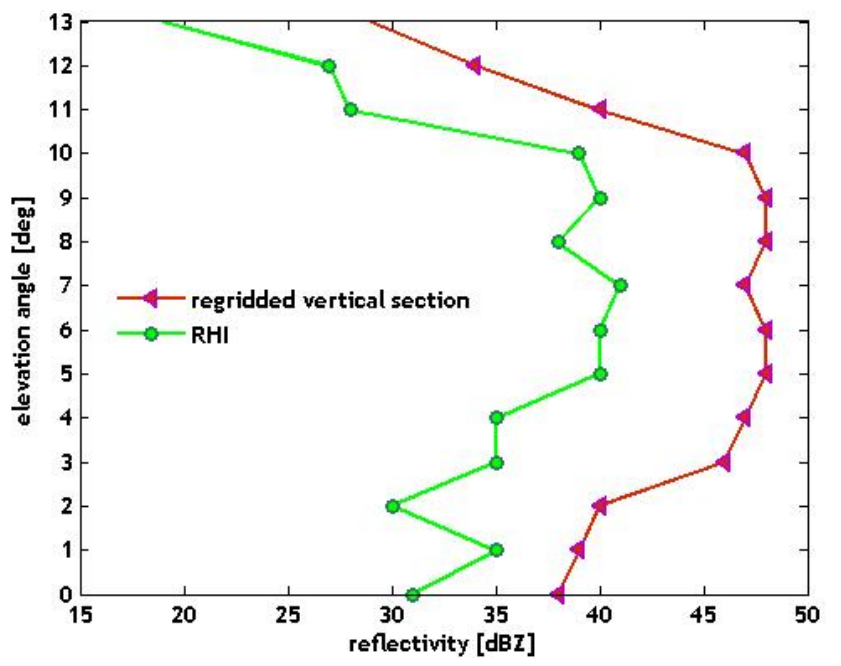

Fig. 4. Vertical profile of reflectivity: green dotted line represents the RHI scan while the purple dotted line indicates the regridded volume section.

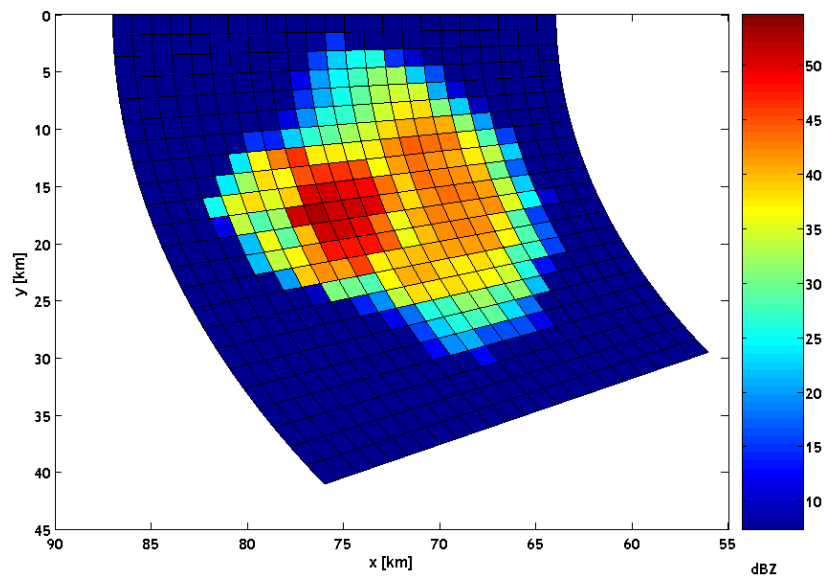

Fig. 5. The "target cell" viewed under a $5^{\circ}$ elevation-PPI scan: the screening effect is taken into account, while an intensely reflecting core can be seen in the left region of the cell.

\section{Structure 1 is taken into account}

\section{Structure 1 is not considered}

The difference between unscreened and screened PPI is displayed in Figs. 5, 6 and 7: despite that the cell shape is well conserved, the more intense core and the southern side appear (the farther from radar site) largely underestimated. Figure 8 shows the main differences between the two data sets in terms of maximum reflectivity ( $59 \mathrm{vs} 53 \mathrm{dBZ}$ ), mean reflectivity (39 vs 28 ) and standard deviation ( 8 vs $9 \mathrm{dBZ}$ ). The vertical reflectivity of the screened cell and of the unscreened one are shown in Fig. 9, while Fig. 10 illustrates the mean reflectivity vertical profile of Structure 1 and the vertical mean difference between an unscreened RHI versus a screened one. Major differences, depending not only on higher reflectivity values of Structure 1 (i.e. a higher rate of

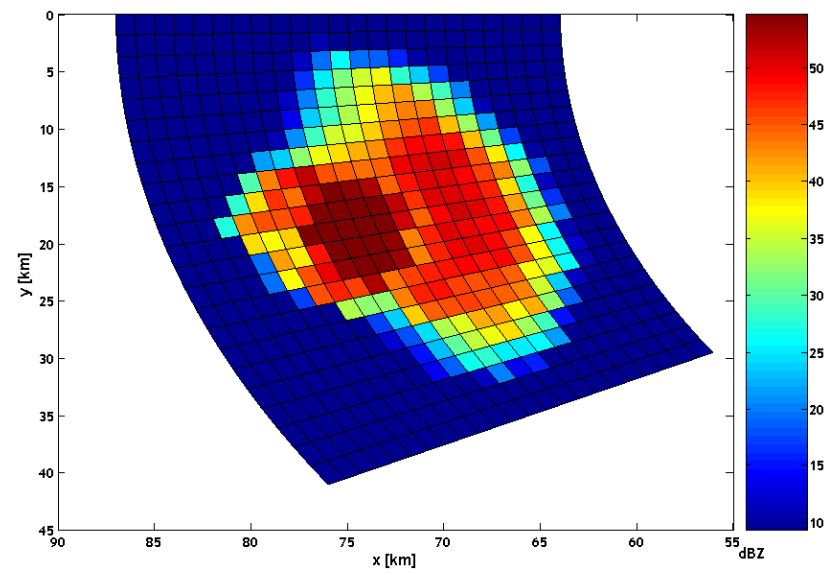

Fig. 6. Again, the "target cell" reflectivity is shown but no screening effect is now considered.

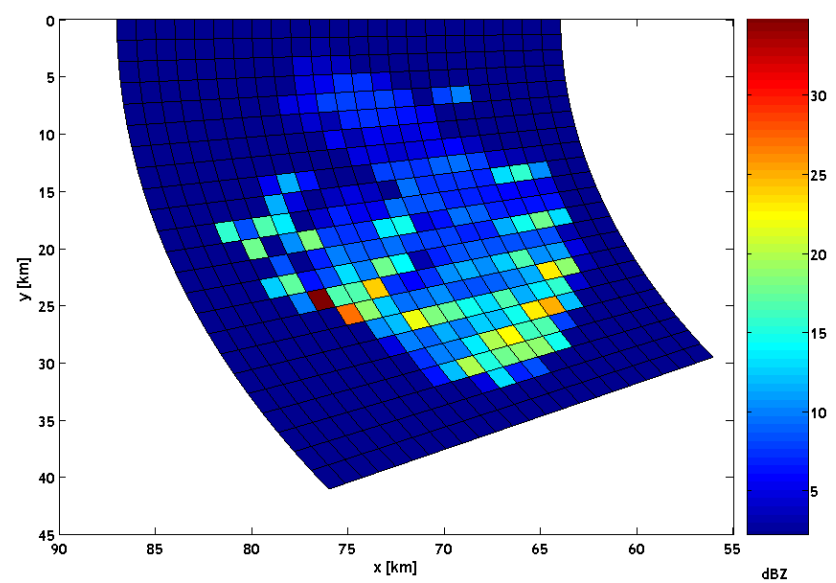

Fig. 7. Difference between unscreened and screened target cell.

screened radiation) but also on screening structure thickness, can be noticed.

\section{Conclusions}

In this work, preliminary results obtained by using LokalModell/RSM chain in simplified atmospheric scenarios are presented. The first experiment was to check RSM capability to reproduce reliably some of the physical problems affecting radar measurements like signal power loss by gaseous absorption (nitrate, molecular oxygen, water vapour) and to quantify its influence on reflectivity measures. The second experiment has been developed so as to determine how and how much a screening effect induced by an intensely precipitating structure could affect radar measures on a target structure.

Future work will be spent in analysing other uncertainty sources like the use of different radar bands (X band and $\mathrm{S}$ band) and, most of all, the use of both different microphysical schemes (the 3-category ice scheme) and different DSDs (Sekhon and Srivastava, 1971; Douglas, 1964; Feingold and Levin, 1986; Ulbrich, 1983) to model atmospheric processes. 


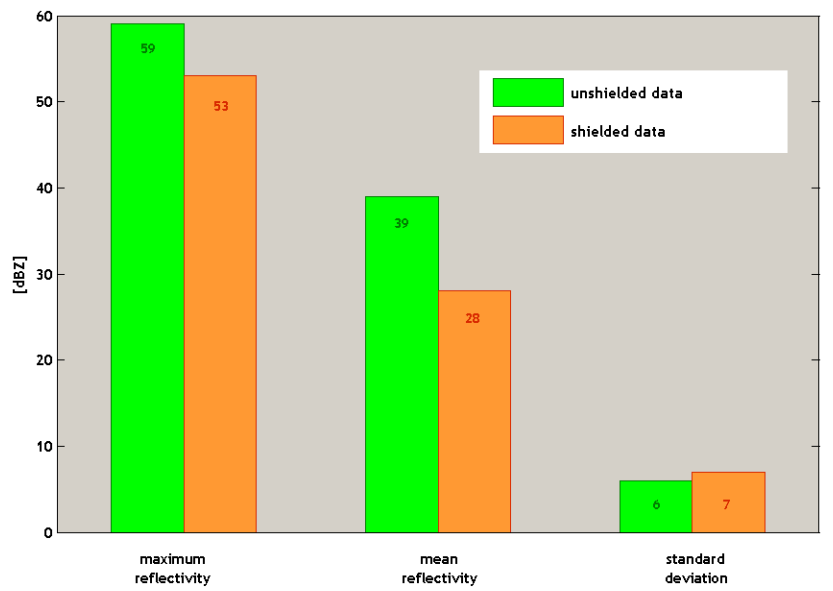

Fig. 8. Maximum reflectivity, mean reflectivity and standard deviation of both unscreened and screened cell.

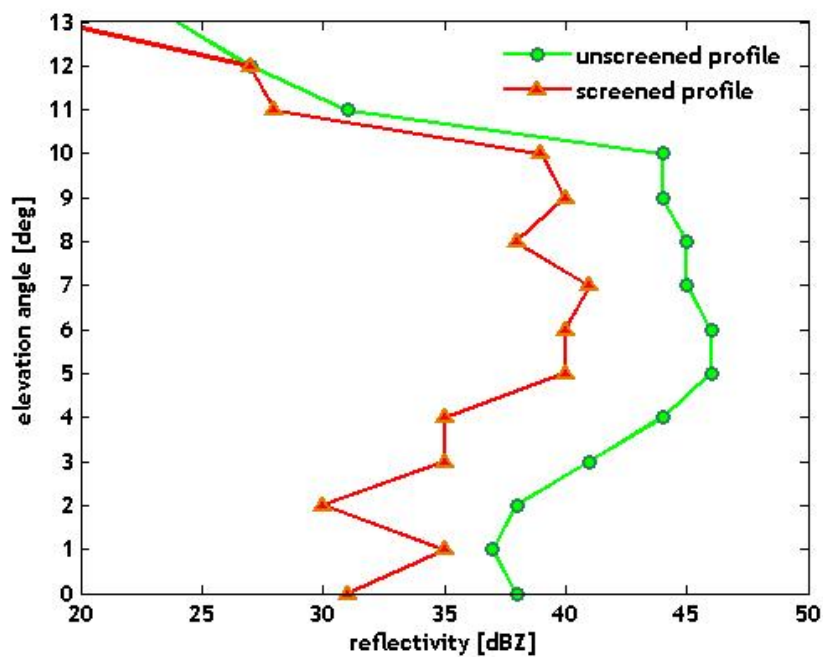

Fig. 9. Vertical profiles of screened cell (red line) and unscreened cell (green line).

Edited by: V. Kotroni and K. Lagouvardos

Reviewed by: S. Michaelides

\section{References}

Chandrasekar, V. and Bringi, V. N.: Error Structure of Multiparameter radar And Surface Measurements of Rainfall Part III: Specific Differential Phase, J. Atmos. Oceanogr. Technol., 7, 621$629,1990$.

Chylek, P. and Ramaswamy, V.: Simple approximation for infrared emissivity of water clous, J. Atmos. Sci., 39, 171-177, 1982.

Douglas, R. H.: Hail size distribution, paper presented at 1964 World Conference on Radar Meteorology, American Meteorological Society, Boulder, Colorado, 1964.

Doms, G. and Schättler, U.: The nonhydrostatic limited-area model LM (Lokal-Modell) of DWD, part I, Scientific Documentation, 1998.

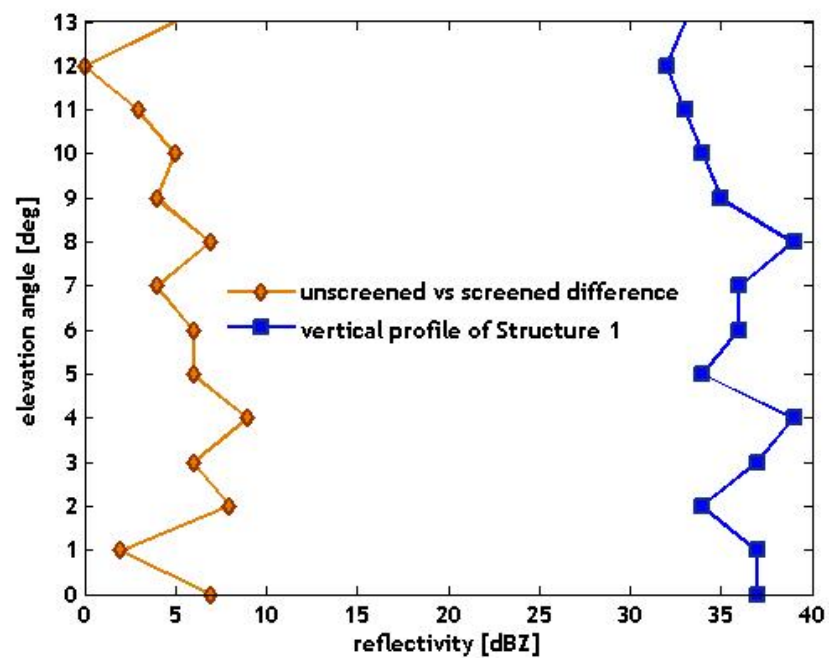

Fig. 10. Mean reflectivity vertical profile of screening structure and mean vertical difference of the target cell.

Fabry, F., Austin, G. L., and Tees, D.: The accuracy of rainfall estimates by radar as a function of range, Q. J. R. Meteorol. Soc., 118, 435-453, 1992.

Feingold, G. and Levin, Z.: The lognormal fit to raindrop spectra from frontal convective clouds in Israel, J. Climate Appl. Meteor., 25, 1346-1363, 1986.

Gunn, K. L. S. and Marshall, J. S.: The distribution with size of aggregate snowflakes, J. Meteorol., 15, 452-461, 1958

Haase, G.: Simulation von Radarmessungen mit Daten des Lokalmodells, Diplomarbeit in Meteorologie vorgelegt, 1998.

Haase, G. and Crewell, S.: Simulation of radar reflectivities using a mesoscale weather forecast model, Water Resour. Res., 36, 2221-2231, 2001.

Keil, C. and Hagen, M.: Evaluation of high resolution NWP simulations with radar data, Phys. Chem. Earth, 25, 1267-1272, 2000.

Krajewski, W. and Chandrasekar, V.: Physically Based Radar Simulation of Radar Rainfall Data Using A Space Time Rainfall Model, J. Appl. Meteorol., 32, 268-283, 1993.

Krajewski, W. and Anagnostou, E.: Simulation of radar reflectivity fields: Algorithm formulation and evaluation, Water Resour. Res., 33, 1419-1428, 1997.

Liebe, H. J.: MPM-An atmospheric millimeter-wave propagation model, Int. J. Infrared and Millimeter Waves, 10, 631-650, 1989.

Marshall, J. S. and Palmer, W. M.: The distribution of raindrops with size, J. Meteorol., 5, 165-166, 1948.

Meetschen, D. and Crewell, S.: Simulation of weather radar products from a mesoscale model, Phys. Chem. Earth, 25, 12571261, 2000.

Mie, G. : Beiträge zur Optik trüber Medien, Ann. Physik, 25, $377-$ 445, 1908.

Sekhon, R. S. and Srivastava, R. C.: Doppler radar observations of drop-size distributions in a thunderstorm, J. Atmos. Sci., 28, 983-994, 1971.

Skaropoulos, N. and Russchenberg, W.: A model of radar backscattering from the melting layer of precipitation, Proceedings of ERAD 2002, 2002.

Steppeler, J., Hess, R., Doms, G., Schättler, U., and Bonaventura, $\mathrm{L}$ : Review of numerical methods for non hydrostatic weather prediction models; Meteorol. Atmos. Phys., 82, 287-301, 2003. 
Ulaby, F. T., Moore, R. K., and Fung, A. K.: Microwave remote Sensing, Active and passive, Addison-Wesley-Longman, Reading, Mass., 1, 456 pp., 1981.

Ulbrich, C. W.: Natural variations in the analytical form of the raindrop size distribution, J. Climate Appl. Meteorol., 22, 17641775, 1983.
Weisman, M. and Klemp, J.: The dependence of the numerically simulated convective storms on wind vertical shear and buoyancy, Mon. Wea. Rev., 110, 504-521, 1982.

Weisman, M. and Klemp, J.: The structure and classifications of numerically simulated convective storms in directional varying wind shears, Mon. Wea. Rev., 112, 2479-2499, 1984. 